\title{
Waste Co-Combustion with a Conventional Fossil Fuel on Power Plants
}

\author{
Roman Bezuglov*, Vladimir Papin, Evgeniy Dyakonov, Elena Veselovskaya, and Vladimir \\ Filimonov \\ Platov South-Russia State Polytechnic University (NPI), Department "Thermal Power Stations and \\ Heat Engineering", 346400 Novocherkassk, Russia
}

\begin{abstract}
The paper has to shed light into understanding the waste useful and it has an aim to review about possibilities how to using different types of waste to generate energy. The paper highlighted the terms, that renewables it isn't energy of the future but waste is - at least the future for the next hundred years. It's very important to use waste by the right way, because of some current methods waste using have a low efficiency. There are several ways of using waste with pretreatment. Nowadays pretreatment includes torrefaction, pelletization, torrefaction of pellets (TOP) and wide spread around the world. It is necessary to compare economic indicators when you want to using some scenario. Using of waste can help us to reduce the pollutions and decrease load to an ambient. There are some advantages to using organic waste to generate energy - it can be considered as a fuel. But it also consists some negatives aspects such as low efficiency due to low thermal values (i.e. specific thermal capacity). Hence, waste using not so unequivocally as it seems at first sight. Thus, here is our understanding for this problem.
\end{abstract}

\section{Introduction and problem definition}

Nowadays there are many approaches to get an energy. In might be conventional ways, for example, traditional thermal power plants with a huge steam turbine and boilers [1,2]. Also now getting wide spread using of renewable energy sources - solar, soil, wind energy - these installations appear all around the world [3-5]. There are some problems with conventional ways to incinerate fossil fuel such as coal, oil and related products [6-8].

One of the most frequently mentioned issue of the modern community is the waste problem. For example, in Russian there are 15-20 million tons of waste, annual come to dumps and this value increase every year. As you known there are a lot of types of waste that's why it's a real big problem to sorting this feedstock. In this article the authors would like to review the whole situation about converting waste to energy.

\footnotetext{
* Corresponding author: bezuglov@npi-tu.ru
} 


\section{The main problems of waste considering as a fuel}

\subsection{The main feature of the waste}

As we know any fuel needs to be prepare before to be fired. Oil has to go through several stages of treatment, natural gas has to be cleared, coal has to be dewatered and grinding. But waste has the more features than any of abovementioned fossil fuels. Waste it might has a several condition phase such as solid, liquid and even gaseous phase. It is necessary to decide at the very beginning - how to use each type of waste! Then, you have to determine organic or non-organic waste do you have. It's important for any fuel - water content of the feedstock. Water refuse to the combustion process so it has to be removed. Also, grinding possibilities need to take into account. And the final things of the waste's main features are the transport and storage aspects - these features have a huge economic impact to the whole energy generation process.

\subsection{Waste Sorting}

When you have huge volume of feedstock - you have to choose the way of treatment. Sorting has to be realized within three stages - sorting while waste collected, sorting while preparing to the treatment, sorting at the treatment stage. There are many methods of sorting that suitable to waste. At the first stage (collect stage) waste can be shared by either people or enterprise. It is necessary to have a quantities of waste point with different tanks - i.e. for paper, plastic, wood, glass and other waste. Through the second stage it might be conveyor, at which one waste be split for different types by mass, weight, volume, dispersion etc. The third stage of waste sorting includes the separation to useful and useless parts.

\subsection{Water in waste}

One of the main issues of the waste treatment is the water remove. Water percentage within municipal solid waste it's about $65-70 \%$ for the summer and to $80 \%$ for the winter condition. This value can be variable due to different conditions of the storage and collecting - inside a building or not. It's necessary to take increase the treatment temperature and operation time to free out this water.

\subsection{Transport and storage features}

Transport issue includes the choice of the transport type. Before you would determine type of the waste treatment you have to calculate economic basis of your method. It's obviously, that waste transportation after the torrefaction it will be cheaper than waste with no treatment because of decrease of bulk volume. Additionally, there is the method of treatment of biomass waste such as hydrothermal carbonization [9-11]. The product of hydrothermal carbonization is the hydrochar that more suitable for the transport and storage. So, it's obviously that need to waste prepare before sending to the combustion object. 


\section{Waste co-combustion with coal}

\subsection{The main problem about waste co-combustion with coal}

One of the main differences between the coal and waste after treatment is the fractions. Coal and waste have a different grindability, it needs to get more resources for waste than to the coal. To grinding waste (biomass or something different) it needs to operate pretreatment which one includes the torrefaction or palletization (or both of them). These operations get additional resources so it effects to the final cost of the energy unit.

It's well known that modern power plant (based of coal) has electric conversation efficiencies over $46 \%$ [12-14]. When biomass is co-combusted in a coal-fired power plant the overall efficiency decreases, due to deterioration of the boiler efficiency. There was provided the experimental boiler efficiency of the co-combustion of coniferous wood biomass $[15,16]$. That happens due to fact that the reduction in boiler efficiency is equal to the reduction in conversion efficiency. This an important issue - to use cheap waste but decrease efficiency of power plant, hence to do conventional process more expensive. But based on existing researches we can argue that more pretreatment results in less deterioration of the boiler efficiency and thus a smaller decrease in overall process efficiency.

Next problem is the instrumental performance - when biomass is applied for cocombustion, a supply system complementary to that of coal has to be designed. Thus, before development project it's necessary to take into account kind of fuel will be combustion at power plant. It's very expensive performance to modernize current installation performance.

\subsection{Secondary problems of waste co-combustion with coal}

One of the problems of fossil fuel using is the greenhouse emissions. Co-combustion of waste has a positive effect on $\mathrm{CO}_{2}$ reduction on the long distant. Low co-combustion levels, as considered, for example in the Netherlands, are effective, but contribute little to the reduction of GHG emissions. Some methods of the waste pretreatment have the best performance, since the number of renewables is the highest, the decrease in GHG emissions is the largest, the increase in energy consumption is the lowest and the energy efficiency shows the smallest decrease. It's a torrefaction and palletization methods. Global warming potentials are expressed in terms of 100 years and replacement of harvested biomass waste and thus sequestration of the $\mathrm{CO}_{2}$ emissions from biomass is not guaranteed. Hence, we can see that in all scenarios two (energy consumption and energy efficiency) of the three indicators perform worse than the reference coal supply chain scenario [12].

\subsection{Waste generating energy with the comparing to renewables}

Last 20 years we observe that renewable energy sources trying to get huge part of the world energy consumption. But if fact, we can see that only few number of regions, predominantly southern regions, can use renewable energy with the proper efficiency [17]. Wind power is also beyond control due to the difficult of its forecasting. Now they say that renewable energy is energy of the future, but that is debatable. In terms of low-efficiency renewables it's hard to say that renewable is the energy of the future. More suitable for this determination is the energy from waste because of humanity is accumulate too much waste that is enough at least for next century. Installations that based on waste has more effective than the similar plants based renewable energy. Additionally, this feedstock receipt is more predictable in the waste case. 


\section{The main conclusions}

As we described above there some problems about co-combustion waste on the coal-fired power plants. It leads to getting thermal schemes more difficult and expensive, also it makes customers doing more thorough processing with waste. Our scientific group expresses an idea about waste conversion into liquid or gaseous fuel. Subsequently this fuel will be using as an additional fuel together with low-rate coal. To this moment the project is realize over three years and next year there will be experimental studies at the lab. There will be researches about what molecules are waste consist of. Lab researches will be carried out with the STA 449 F5 Jupiter synchronous thermal analysis instrument. This analysis instrument combines differential scanning calorimetry or differential thermal analysis and thermogravimetry in a single measurement. The STA measures heat flux and mass measurements under completely identical conditions. Additionally, the device for synchronous thermal analysis via an adapter is integrated with the QMS Aëolos Quadro quadrupole mass spectrometer, which allows the analysis of evolved gases in real time.

Thus, people always find new ways to reduce operational costs and use recourses that they are already have. So, extraordinary waste dumps all over the world is the "mines" which we can use to mine new fuel - fuel of the future.

The research described in this article has been financed by a grant of the Russian Federation President to the young scientist and graduate students who are carrying out perspective research and development in the priority directions of modernization of the Russian economy for 2018-2020 (Project No. SP459.2018.1).

\section{References}

1. Shaposhnikov, V.V. Increasing efficiency of CCP-based TPP with injection of dry saturated steam from recovery boiler into regenerator / V.V. Shaposhnikov, B.V. Biryukov // Journal of physics: conference series. - 2017. - № 891.

2. Shaposhnikov, V.V. On the efficiency of heat and electric power plants based on combined-cycle plants with overexpansion of the working fluid in the gas turbine and injection of steam into the gas path / V.V. Shaposhnikov, B.V. Biryukov // Chemical and petroleum engineering. - Vol. 54. - Nos. 1-2. - May. - 2018.

3. V.V. Papin, R.V. Bezuglov, V.N. Baltyan, Energy efficiency of the heat and power complex for highly efficient use of secondary and renewable energy resources, Material Science Forum, 2018. - Vol. 931, - P. 933-937.

4. V.V. Papin, R.V. Bezuglov. E.V. Veselovskaya, The test bench of a cascade heatpump installation of a heat power complex for highly effective use secondary and renewables, MATEC Web of Conferences. - 2018. - Vol. 224: ICMTMTE 2018. - Access mode: https://doi.org/10.1051/matecconf/201822402056.

5. N.N. Efimov, V.V. Papin, R.V. Bezuglov. Micro Energy Complex Based on Wet-Steam Turbine / Procedia Engineering. Vol. 150 (2016), p. 324-329, http://dx.doi.org/10.1016/j.proeng.2016.07.022

6. Kaderov, K.K., Korchagina, M.V., Kireev, S.O., Nikishenko, S.L. // Solution of Problems of Gasketing of Joints of Units of Machines and Equipment of Oil and Gas Enterprises When in Use in High- and Low-Temperature Regimes / Chemical and Petroleum Engineering, 2018 
7. Shahzad Baig K Yousaf M // Coal Fired Power Plants: Emission Problems and Controlling Techniques / Journal of Earth Science \& Climatic Change 2017, DOI: 10.4172/2157-7617.1000404.

8. Stepanov, V.N., Kireev, S.O., Korchagina, M.V., Efimov, A.V. // Analysis of Efficiency of a System for Heating the Water-Supply Pump and High-Pressure Pump of a Pumping Station from the Exhaust Gases of an Internal Combustion Engine / Chemical and Petroleum Engineering, 2020

9. Hari Bhakta Sharma, Ajit K. Sarmah, Brajesh Dubey // Hydrothermal carbonization of renewable waste biomass for solid biofuel production: A discussion on process mechanism, the influence of process parameters, environmental performance and fuel properties of hydrochar / Renewable and Sustainable Energy Reviews 123 (2020).

10. Y. Wang, C. Jiang, Y. Liu, D. Wang, J. Liu, The effect of heat and moisture coupling migration of ground structure without damp-proof course on the indoor floor surface temperature and humidity: Experimental study / Energy and Buildings vol. 158, 2018, Pages 580-594, https://doi.org/10.1016/j.enbuild.2017.10.064

11. Roshchin A.V., Grigoriev V.S., Sagittarius A.V., Nikolaev A.I., Rayevskaya E.G., Usin V.V., Supercritical hydrothermal destruction of the dangerous substances containing organic chemistry and waste with the prospect of utilization of energy potential of gaseous products, Chemical physics, V. 36, № 7, 2017, p. 18-24.

12. Jan H. Miedema, René M.J. Benders, Henri C. Moll, Frank Pierie // Renew, reduce or become more efficient? The climate contribution of biomass co-combustion in a coal-fired power plant / Applied Energy 187 (2017) 873-885.

13. Lin T, Rodríguez LF, Davis S, Khanna M, Shastri Y, Grift T, et al. Biomass feedstock preprocessing and long-distance transportation logistics.

14. European Commission. State of play on the sustainability of solid and gaseous biomass used for electricity, heating and cooling in the EU (SWD 259 final); 2014.

15. Pronobis M. The influence of biomass co-combustion on boiler fouling and efficiency. Fuel 2006;85(4):474-80.

16. Pronobis M, Wojnar W. The impact of biomass co-combustion on the erosion of boiler convection surfaces. Energy Convers Manage 2013;74:462-70.

17. Ümit Sağlam // The Efficiency Assessment of Renewable Energy Sources with Data Envelopment Analysis / 2018 Annual Meeting of the Decision Sciences Institute Proceedings, Chicago IL, November 2018. 